be named after Dr. Osler, this to be a testimonial to him among his friends.

Committees have been formed from the members of the society in Baltimore city and in different counties of the state, and liberal contributions are being made by the thousand or more members throughout the state. At the present time we have in hand, either in cash or pledges, about $\$ 42,000$. Our aim is to raise $\$ 50.000$ by April 30 , the other $\$ 50,000$ we believe will be contributed by certain wealthy men who have promised to aid this movement. The campaign is being carried on not only among the medical profession, but appeals are also being made to the laity, to the prominent business houses, and to the large drug houses in the city. The Maryland Pharmaceutical Association will probably raise a fund amounting to nearly $\$ 5,000$, and will have a room in the building for the use of its members.

I trust that you will find a space for this letter in your columns, so that the impression which has been given that this is to be strictly a memorial to Dr. Osler may be corrected. It does not lessen in any way the esteem which every doctor has for him, but it is only fair to the profession in general to state that this building is being erected through their efforts, and will be a testimonial to the energy and liberality of the doctors of Naryland. Artiúr P. Herring, Chairman Soliciting Committee.

\section{Intracranial Tumor Due to Traumatism.}

Florevee, Italy, Nov. I, 1907.

To the Editor:-I was much interested in the case of cerebral tumor resulting from trauma, reported in The JournaL, Oet. 19,1907 , page 1361 , by Dr. Leszynsky and commented on editorially in the same issue. The report reminded me of the first case of cerebral surgery in which I ever operated. The cause of the tumor-in my case, a fibroma-was the same, viz., trauma from a small splinter of bone from the inner table of the skull-a very rare fracture. In Dr. Leszynsky's case only two years elapsed between the accident and death; in my own over twenty years elapsed between the accident and the operation. The bone splinter was found at operation, adhering to the dura from which the fibroma arose. The operation was done in the autumn of 1887 and was reported in the American Journal of the Medical Sciences in. I think, 1888 or 1889. Those interested in such cases will be glad to learn that up to the end of 1906, the date of my last information, the patient was still living-over nineteen years after the operation-and in as good health as could be expected after such a history.

W. V. KEEN.

\section{Book Notices}

Principles and Practich of Modern Surgery. By Roswell Park, M.D., Professor of Surgery in the University of Buffalo, Buffalo. N. Y. In one imperial octavo volume, 1072 pages, 722 engravings and 60 full page plates in colors and monoch
Cloth, $\$ 7.00$ net. Lea Brothers \& Co., Philadelphia. 1907.

This book from the hand of a master of his art is one of the most welcome additions to our medical shelves in recent years. A work written entirely by one author who is thoroughly conversant with the many details of his specialty is far more satisfactory than one written by a number of surgeons. Dr. Park's varied and long experience renders him peculiarly fitted to write a book on the entire subject of surgery. The work is well balanced and gives the reader not only the benefit of the author's extensive knowledge of surgical pathology, but also describes the details of diagnosis and treatment in a manner born of ripe experience. The only regret is that comparatively few original illustrations have been employed. The book should serve the student and practitioner as a most valuable and anthoritative guide. The chapters on abdominal surgery are especially satisfactory and thorough. The book is a worthy successor of the "Surgery by American Authors," edited by Professor Park, which ran through three editions. The popularity of this system will be fully shared by the present single volume.
Pharmacology and Therapeutics. Ry Reynold Webb Whlcox M.D. ILL.D., Professor of Medicine at the New York Post-Graduat Medical School and Hos ital, etc. Seventh Edition, Revised, with Index of Symptoms and Diseases. Cloth. Hp. 885. Price, \$3.00 net. Philadelphia: P. Blakiston's son \& Co., 1907.

This companion volume to "Materia Medica and Pharmacy," the latest edition of which recently appeared, has been revised with a view to condensation so far as compatible with clearness. The two works combined offer a complete presentation of the subject of materia medica and therapeutics. In the present volume drugs are taken up according to a pharmacologic classification and their action first given, after which follows the therapeutic uses deduced therefrom. It is reassuring to see in this text-book a correct presentation of the facts concerning lithium as a uric-acid solvent, and we hope that this may go far toward removing some of the blind use of this and other uric-acid solvents which has been so common in the past. The true status of inorganic and organic iron is also recognized. The book seems to be browght well up to date, and affords a useful guide to the studs $t$ and practitioner in the treatment of disease.

Clinical Therapedtics. A Handbook on the Special Treatment of Internal Disease. Bv Alfred C. Croftan. Author of "Clinical
Urinology." Second Edition, Revised. Cloth. Pp. 626. Price, $\$ 5.00$. Chlcago: Cleveland Press, 1907.

The first edition of this book was issued only a few months ago and is quickly followed by this second edition. The author has written a book on therapentics and no attempt is made to cover the field of materia medica or pharmacology. The book aims to give practical directions for the treatment of the sick. If we express a criticism it is that the various remedies are not always valued or their worth expressed, but are simply enumerated and good methods of administration described. For each disease discussed the various medicines and medical procedures which are still recommended and used by clinicians are described. Non-medicinal therapentics is not neglected; on the contrary, it is discussed fully. The best chapters are those devoted to diseases of metabolism and of the kidneys. Only the commonest infections are considered, and diseases of the nervous system are not included.

Heart Disease and Blood Pressure. A Practical Cansideration of Theory and Treatment. By Louis Fangeres Bishop, A.M. M.D., Clinical Professor of Heart and Circulatory Diseases, Ford ham University School of Medicine. New York City, etc. Secon Fdition. Cloth. Pp. 120. Price, \$1.00. New York: E. B. Treat

This is the second edition of this little volume and while there is much of interest in it, it is surprising that a second edition should be needed. The book does not discuss heart disease, nor methods of measuring blood pressure, nor is its scope that of blood pressure in heart disease; but it discusses some of the conditions of high and low blood pressure, and, in most general terms, methods of treatment. The author frequently expresses himself as though high or low arterial tension were a disease instead of a symptom of many different ones. In discussing treatment, however, he does consider the diseases and the treatment of them which may be necessary to remove a disturbance of tension. The book contains nothing which is strikingly original; on the other hand, is not a satisfactory compilation of what is known of the subjects embraced in its title.

\section{Queries and Minor Notes}

Axoxymous Commexications will not be noticed. Queries for this column must be accompanied by the writer's name and ad dress, but the request of the writer not to publish name or address will be fatthfully observed.

\section{KISSINGEN SALTS IN OBESITY.}

FredericksburG, OHIO, Nov. 15, 1907

To the Editor:-Please tell me whether or not there is anything in "Kissingen salts" that would be depressing to the heart or other wise injurious in ordinary doses? Are such salts efficlent in the treatment of obesity? Where can I obtain up-to-date information on dieting for obesity. W. H. MERRIAMI.

AxSWER.-Artificial Kissingen salt and effervescent artificial Kissingen salt are now official in the National Formularly under the titles Sal Kissingense-Fuctitium and Pulvis Salis Kissingensis Fac- 